\title{
Concept test method to assist engineering students to involve users in a user-centered design project
}

\author{
Thales Martins Ponciano ${ }^{1}$, Carina Campese ${ }^{1 *}$, Janaina Mascarenhas ${ }^{1}$ \\ ${ }^{1}$ Departamento de Engenharia de Produção, Escola de Engenharia de São Carlos - EESC, Universidade de São Paulo - USP, São Carlos, SP, Brasil
}

\begin{abstract}
Including user information in products that can be produced and sold for profit is critical to user-centered design. However, there is in the current literature a lack of methods to help designers in the initial phase of development. This lack is more critical when designers and engineers have little or no expertise in involving users in the Product Development Process (PDP). This paper presents a new method to evaluate product concept through the involvement of users with low-fidelity prototypes. The method was used in a case research with engineering students in a learning environment at a Brazilian public university. The qualitative analysis of the case research took place through the monitors' audios, method chart results, and groups' reports. These data revealed the effectiveness of the Concept Test method to assist groups of developers. Using prototype functionalities to involve users has brought relevant information to the design and it is extremely beneficial for engineering students and users without a level of expertise. Concept test is believed to be effective for the developer team to involve users in their projects through prototypes, but they should work as a complement to the requirements management methods in the other stages of development.
\end{abstract}

Keywords: usability, engineering students, product concept development, prototype, UCD

\section{Introduction}

User involvement is crucial to the development of successful products. It is known that this involvement must be done previously (Viitaniemi et al., 2010), from understanding the need to the final evaluation of the products. Authors such as Eppinger \& Ulrich (2015), Gulliksen et al. (2003), and Viitaniemi et al. (2010) explored the involvement of users at the beginning of the design and they use engagement to build empathy for developers. This can be seen in some of the main methods addressed in the early stages such as persona, empathy map and user stories (Campese, 2019).

Even taking a UCD approach, developers have challenges to ensure that their design decisions consider users. The insertion of prototypes, from MVPs to rustic prototypes, has proved to be an excellent way to reduce uncertainties in relation to users and consequently ensure that their perspective is considered (Wilkie, 2014).

However, according to Rudd et al. (1996) and Ahmed et al. (2003), prototyping is a cyclic and evolutionary process, in which more than one type of prototype must be developed throughout the product development process. This factor makes prototyping a complex activity for nonexpert developers. In the early stages of the PDP, it is common to adopt low-fidelity prototypes, which are less developed product represented by paper, storyboard, draft or sketch prototypes. Despite the use of prototypes in the early stages, most of small companies do not use a specific method during this interaction.

One of the main activities in the early stages of development is the concept evaluation at the beginning of the design (Eppinger \& Ulrich, 2015). This concept in mature industries such as automotive is done through mockups on real scales. However, in companies that do not have financial resources or maturity with prototyping, the concepts evaluation is restricted to the product development team. Since this step is decisive for having a usercentered product, companies that have no maturity lack methods to involve users with prototypes to evaluate product concepts.

In the research carried out by Campese et al. (2015) it was seen that most methods of user involvement do not address this stage of concept evaluation. So what information about the product concept could be evaluated in an interaction with users? And which aspects of the product concept are fundamental for the opinions of users to be heard?

This article aims to present a new method of evaluating product concept through the involvement of users with low-fidelity prototypes. In order to evaluate the proposed method, a group of engineering students who

Received: February 24, 2021. Accepted: April 1, 2021

*Corresponding author: Carina Campese. E-mail: carinacampese@yahoo.d 
represent nonexpert naive users was chosen. This choice was deliberate because it is known that industries with a high maturity in UCD have experienced teams, and as the proposed method aims to enable user involvement even with teams that have no experience in UCD, it was necessary to choose such a sample.

This paper has two contributions: from the theoretical point of view it presents the discussion about the information that the user can contribute in the evaluation of concepts; and from an empirical point of view, bring a simple and effective method for evaluating prototypes.

\section{User-centered design and product development}

User-Centered Design (UCD) in the literature is defined as a philosophy (Abras et al., 2004; Barrington, 2007; Rippon, 2006), an approach (Siebenhandl et al., 2013; Viitaniemi et al., 2010; Mao et al., 2005; Preece et al., 2002), a principle (Siebenhandl et al., 2013; Gulliksen et al., 2003) or a process (Gulliksen et al., 2003; Rippon, 2006; Göransson, 2001). Despite the different definitions, the UCD is based on improving the development of products, services, or systems that have the user as the focus of this process. In a recent study, Campese et al. (2020, p. 47) suggest a common understanding, that UCD is

[...] an approach for user involvement comprising principles that guide the establishment of goals and the accomplishment of activities, enabling user information and knowledge to be obtained and incorporated in the design process, using methods and techniques identified in the body of knowledge of this area.

ISO 9241-210 (International Organization for Standardization, 2010) also defines the term as an approach. According to the standard, UCD acts in the development of interactive systems to make the systems usable and useful, focusing on users to understand their requirements and experiences. The standard highlights the importance of understanding and applying human factors, knowledge, and usability techniques for the development of systems that improve human well-being, user satisfaction, accessibility, and sustainability. ISO 9241-210 (International Organization for Standardization, 2010) and Göransson (2001) establish some activities to incorporate the UCD approach: analyze user needs and requirements, design for usability through prototyping, evaluate the product concept with users, and feedback.

A product that meets the different needs of customers can benefit not only the end-user but also other stakeholders, as it makes the product more competitive and accepted and may require less maintenance (Barrington, 2007). Thus, it is clear that with the increase in market competitiveness, a product with greater usability can be a great differentiator for those who have purchasing power. According to the literature, neglecting usability can generate consequences that impact the cost of the project, such as loss of time, rework, waste, and inefficiencies (Barrington, 2007).

The prototype in the design process refers to the physical representation of a solution and aims to perform tests on something that will be produced (Baxter et al., 2015). In this sense, the prototype is seen as a product, or part of one, and can serve as a model for generating a finished product (Chrissis et al., 2013). Through prototypes, it is possible to understand, evaluate, and communicate the product's attributes for improvement purposes (Alcoforado et al., 2015).

Norman (1988) highlights the importance of the prototype for communication between people in development activities. For the author, physical representations are extremely important to support people in carrying out cognitive activities. The author also highlights the importance of perception, creation, and evaluation activities through prototypes (Norman, 1988). The use of physical objects can provide more information to developers than written and abstract specifications (Gladden, 1982).

The prototype can help identify problems in development both at the beginning and at the end of this process. Because prototypes can be created quickly and at low cost, it is recommended to use it in the early stages of development (de la Hidalga et al., 2016; Kelley, 2005; Neubeck et al., 2016).

Rudd et al. (1996) argue that product specifications are usually made before the prototyping process begins. However, when developing innovative products, companies need to identify product specifications when using prototypes (Schrage, 2014). The prototype is an important tool for developers to learn and identify customer needs and, thus, define the concepts that the product needs to have (Nguyen-Duc et al., 2017). The use of prototypes in the design process allows users and developers to discuss a proposed product, before it is in its final form, avoiding customer dissatisfaction. Therefore, prototyping can play an important role in systems with a user-centered product and service development.

According to Camburn et al. (2015), although prototyping represents one of the biggest sunk costs in the design process, little importance is given to the topic in the literature. For the authors, prototyping represents, in the context of product development, the systematic elaboration, and testing for product concept development. 
This concept is important to establish product viability and improve the detailed design of the models from before the production phase (Camburn et al., 2015).

The term 'product concept' is also associated with prototyping by other authors. Crawford \& Di Benedetto (2015, p. 109) define the concept of a product as a verbal expression or through a prototype that the consumer wins or loses. The authors relate the product concept to three main pieces of information: benefit, technology, and form. The importance of each piece of information for the product concept depends on the industry it relates to (Crawford \& Di Benedetto, 2015). In the automotive industry, for example, the authors report that the suppliers of components for cars are informed by the automakers which benefit a certain item must have, and therefore, they must work on the technology and the way to innovate. Unlike the food industry, where technology and form are known, but the taste of consumers, in this case, the benefit, becomes the main variable (Crawford \& Di Benedetto, 2015).

The product concept is treated as a synonym for product scope by Rozenfeld et al. (2006, p. 522). For the authors, these terms deal with the written and visual description (prototyping) of the main characteristics and the benefits of the product for consumers. These features include information such as 'what the product is' and 'what it's for'. Rozenfeld et al. (2006) report that this information is obtained through analysis of competing products, market trends, and consumer behavior.

Cooper (2011) defines the concept as "what the product does and how it should be" according to the users' needs. For the author, this information must reflect the desires of the market to be reached. The concept should cover product specifications such as benefits, value proposition, performance characteristics, and design requirements (Cooper, 2011). The author also argues that this information can be obtained through the study "Voice-of-customer" (which includes interviews and ethnographic studies with users) and refined in the "Concept test with users" carried out through prototyping.

Like other authors (Cooper, 2011; Crawford \& Di Benedetto, 2015; Rozenfeld et al., 2006), Eppinger \& Ulrich (2015) also highlight the importance of developing product concepts in the initial phases of the design process. For the authors, the initial phases contain interrelated activities that begin with the identification of consumer needs and end with the proof of concept through prototyping (Eppinger \& Ulrich, 2015). Despite the prominence, the authors do not present a method for using prototypes in the concept test with users in product development.

Studies reveal that planning to involve users with prototypes is even more critical when the developer team is made up of engineering student (Miller \& Summers, 2013; Deininger et al., 2017). Despite understanding the reasons for using prototypes, Deininger et al. (2017) identified difficulties in a sample of engineering students in planning how they would use the prototypes. The authors concluded that this fact does not correspond to a mistake on the part of engineering students, but it may indicate that the participants have not yet fully conceptualized the value and the wide uses of prototypes. The difficulty in planning the use of prototypes by engineering students is related to often consideration of prototypes as models to be created towards the end of a design process, in contrast to expert designers (Deininger et al., 2017). Methods that help engineering students to plan user engagement activities with prototypes are therefore seen as good practice.

\section{Methodology}

The objective of this research is to apply the Concept Test method to support the development of prototypes concepts. The proposed method is based on UCD theory, in particular evaluating the product concept with users and giving feedback. The sample of cases chosen to apply the method was composed of engineering students who were taking the second year of Materials Engineering course at a public university of São Paulo, Brazil. The engineering students took the discipline of Work Design and Ergonomics which, in terms of learning assessment, proposed the development of trash cans to be used in public environments and food courts. Fifty-three engineering students were divided into eight groups, composed of six or seven members in each. The discipline occurred from August to December in 2019.

During this period, students were asked to perform the test following 3 steps: planning, execution and evaluation of results. For a better analysis of the method applied, postgraduate researchers were defined to monitor the activities developed by the groups. Each researcher was responsible for a team in the planning and execution steps of the tests. The researchers used cell phones to record all the advent of the test following a protocol (Appendix 1). At the end of the tests, 143 audios were recorded.

The results assessment test phase was carried out without monitoring, and the teams were instructed to develop a test results report. All reports were analyzed, as well as partial test planning deliveries. 
A qualitative approach was defined to evaluate (1) the usability of the proposed method and (2) the results generated by its use. To carry out the qualitative evaluation, the Miles et al. (2014) content analysis approach was used and, MAXQDA coding software was defined. Figure 1 below shows the logical structure of the coding.
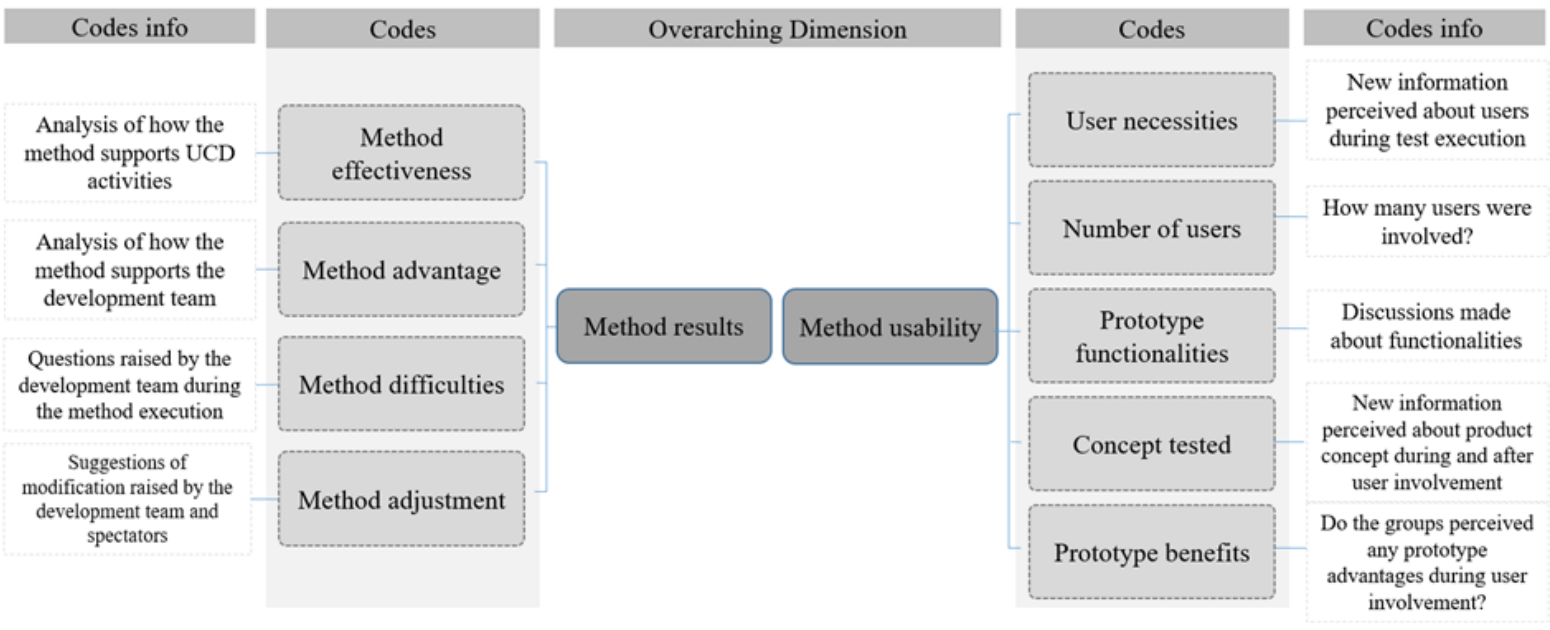

Figure 1. Coding structure at MAXQDA.

The central part of Figure 1 represents the qualitative approach of this study. Figure 1 also contains the codes used to analyze the audios recorded by the monitors, the method completed after the user involvement and the groups' report. The codes info helped the researcher setting a conceptual relationship on the codes. All codes info were established according to the objective of this case research, which aims to answer: "does the method developed to support the involvement of users with prototypes?", "What benefits did the method bring to groups of engineering students?" and "how can the method be improved?". This emphasis the study as qualitative analysis of an empirical research that uses multiple cases as a unit of analysis in a real situation (Karlsson, 2016). This approach is built on an in-depth interpretation of reality through analysis of research evidence (Karlsson, 2016).

\section{Results}

In this article, we seek to introduce the Test of Concept method to support groups of developers to engage users to improve development. We used engineering students who, through a case research, used the method to develop ergonomic dumps to be handled in public environments (such as squares and sidewalks) and food courts. This project is part of a discipline in the Materials Engineering course at a public university and is based on the involvement of users in product development. The data obtained are presented in four sections.

First, the method (its objective, template, and step by step) is presented. Then, the pre-planning, test planning, and test execution are presented with the groups of engineering students. The results obtained in the analysis of the three data sources (transcribed audios of the monitors, group report, and completed method) are presented in these four sections.

\subsection{The method}

The Concept test was designed to make it easier for initial tests of product concepts with users. The method proposed is intended to facilitate user involvement through prototypes for the developer team who seek to minimize errors, discover new requirements, and increase the usability of their products. The method allows the developers' team to organize product solutions from users' needs into functionalities and establishes that users test them through a free test, guided, and interview. The Concept test example is represented by Figure 2.

The example of the Concept Test on Figure 2 is the development of a new handcuff. The example above indicates only one functionality represented by the yellow note, the "handcuff lock". In the study research of this work, the group of engineering students used three or four functionalities in their tests. The example on Figure 2 also indicates the use of all three tests: free, guided and interview. The tests usage depends on the objective of the design project.

The result of the free test provides the developer team with cognitive aspects of the user's interaction with product functionalities. This represents what users are looking at, thinking, doing, and feeling. The developer team must plan what possible activities that the user is expected to perform and insert them into the method chart. We suggest the use of sticky notes to insert all information on the method chart. When interactions happen, observers might take notes of what users say and do, noting places where they encounter difficulty and their actions or words. 


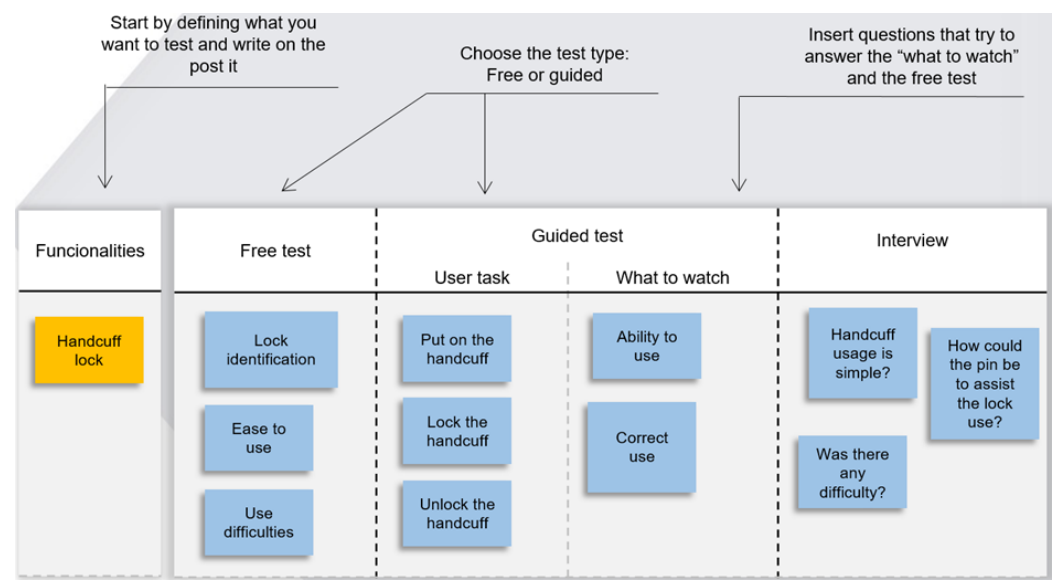

Figure 2. Concept Test example.

The guided test allows the team to direct the user's interaction with the product functionalities to obtain specific results of a task. The task in the guided test represents the sequence of actions (physical or cognitive) the user must perform to achieve a goal. The developer team must plan the actions and the possible results of these actions and insert them on the method chart, before interacting with the user.

Guided tests or free tests can be preceded by an interview to help the developers' interpretation. Interviews are used to conduct questions to obtain the necessary information for the team of developers about a certain functionality. As with other tests, the team of developers must plan questions that are aligned with project objectives.

\subsection{Pre-planning phase}

Before applying the method, the groups developed initial prototypes obtained during the discipline of Work Design and Ergonomics to solve the users' needs. All information on needs, solutions, and prototypes were obtained in 4 stages (Figure 3):

1) Initial observation form: It refers to the initial observation of the aspects that refer to the use of the trash. The report contains the initial methods and procedures that the groups will use to collect product and user information;

2) Defining user needs: It aims to describe the process of observation and information collection (e.g. place of observation, number of users observed, protocols used), the profile of the target user, and discussion about the user. Methods used by groups: observation, survey, interview, and group discussion;

3) Gate: The groups present the solution ideas that cover the users' needs and a group of experts decided to maintain or dispose of ideas. The experts consist of three members of a company specialized in recycling, the professor, and two discipline monitors;

4) Solutions alignment and prototyping: It refers to the description of the reformulated solution ideas after the experts' suggestions. The groups also build physical and virtual prototypes.

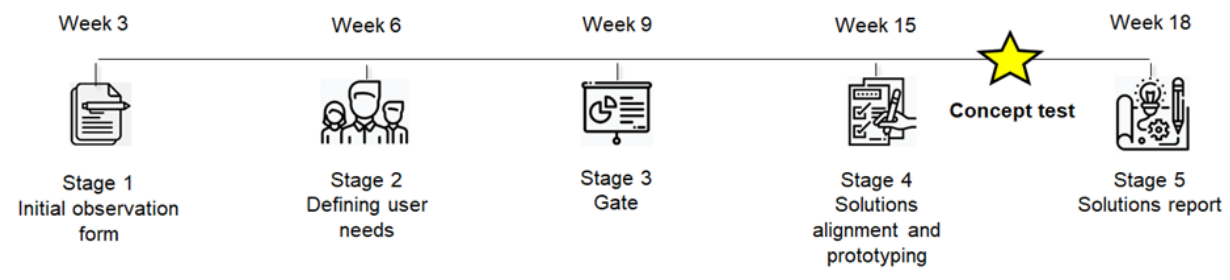

Figure 3. Groups activities during the discipline.

Stage 5 refers to the report of the result of the solution ideas after the users' involvement. The groups also inform in this report what the prototypes will look like after the improvements identified after the Concept Test application. Concept test was applied between the 15th and 18th week.

\subsection{Test planning}

The test planning activity refers to the first stage of the Concept Test. The groups received an example of the method (Figure 2) to fill out the chart, the method chart (Figure 4) and used the following materials: colored adhesive notes, pens, brushes, and the prototype (physical and virtual). 


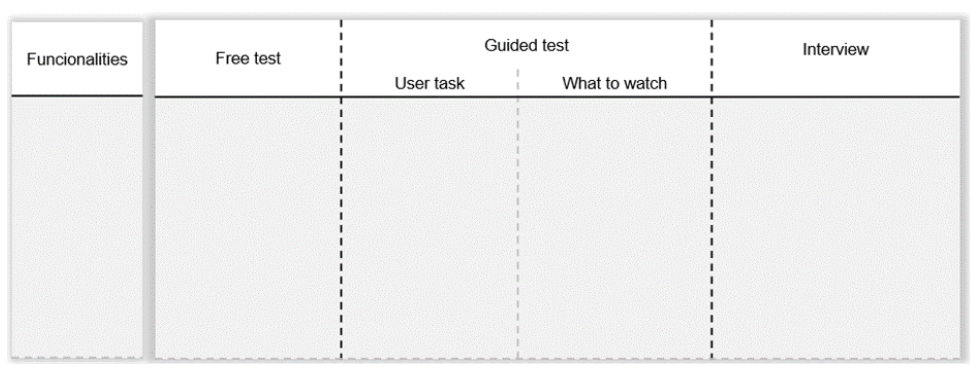

Figure 4. Concept Test chart.

The objective of the method and the steps were presented to all members of the groups simultaneously using the presentation of the Microsoft PowerPoint software in a projection. There was an emphasis on explaining the prototype functionalities to ensure that all needs raised by the groups could be tested as a function using the method.

The groups completed the chart on November 18th, 2019. The activities, comments, and reactions of the group members were reported by the viewers through the audios. The monitors' audios demonstrate that the group that demanded the longest time for this activity took 52 minutes and the smallest, 35 minutes. Figure 5 shows two of the groups performing the test planning activities.
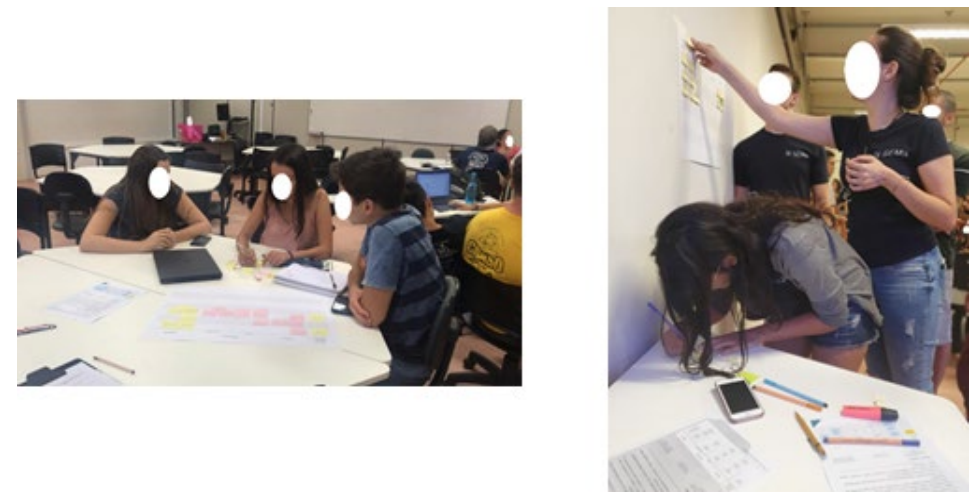

Figure 5. Groups performing the test planning activities.

\subsection{Test execution}

The execution of the test with users refers to the second stage of the Concept Test method. This step is performed after filling on the chart with information about the tests to be performed with users. The user involvement took place on November 25, 2019 from 2:30 pm to 5:30 pm.

The groups were separated into stands containing: prototype, method board, notepaper, and pen. All groups also used notebooks to help record reactions and comments from users about the prototype. The form of recording user information was freely established by each group. As with test planning, monitors reported reactions and comments from group members and users during the test run (Figure 6).
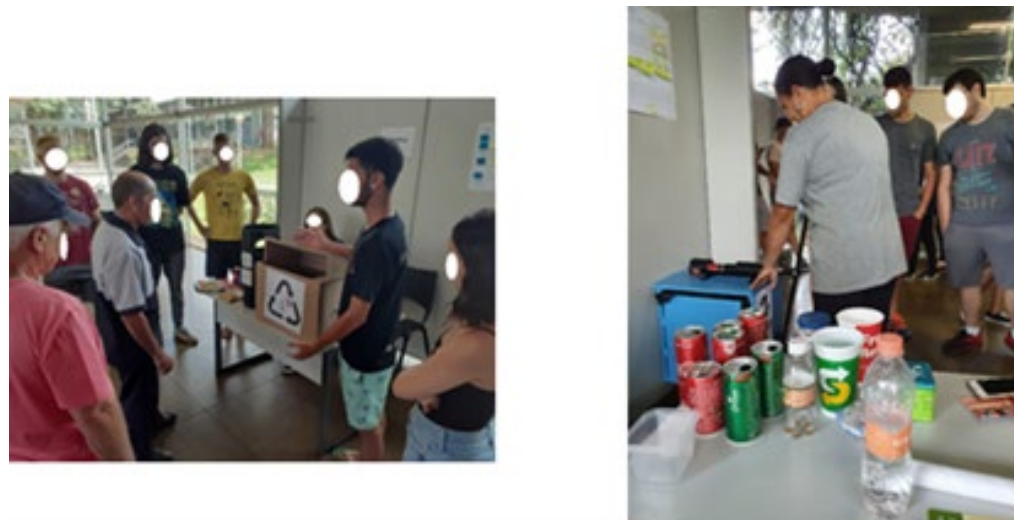

Figure 6. Users' involvement in the test execution stage. 
A total of 64 male and female users aged between 18 and 65 years were involved. Through telephone contact, 18 workers were recruited to clean and maintain the university campus. The remaining 46 users were university students, professors, and people who passed through the campus and agreed to take the tests. The users involved do not have specific technical skills related to the manufacture or dumps handling. There was disclosure on social networks and communication channels of the college about the recruitment of users for the prototype testing activity.

Table 1 contains all users' needs identified per groups in the pre planning phase. On the second line is informed the functionalities' names used to perform the test. Those functionalities were defined by each group on the planning phase. Table 1 also contains the number of user involved on the execution phase and a prototype (virtual or physical) photo. All prototype photos were taken on the pre-planning phase, before completing the method chart and user involvement. Each number on the photo represents a prototype functionality indicated on the second line.

Table 1. Groups results.

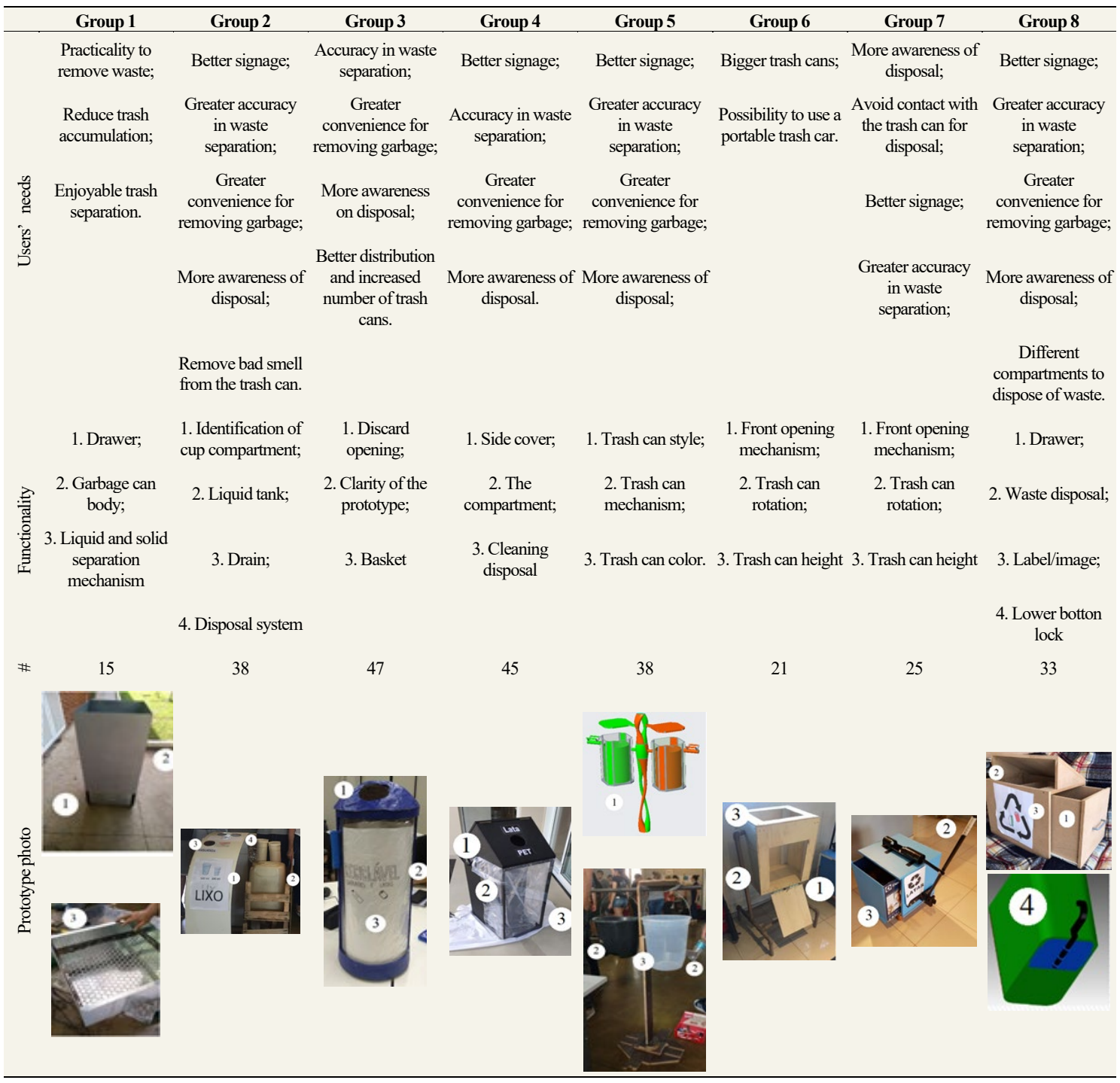

\section{Discussion}

Gulliksen et al. (2003) suggest the development of simple representations of design to assist the way the user is involved and, consequently, the evaluation of the product by the user. To test their prototype concepts, the groups of engineering students used 26 prototype functionalities in total. Prototype functionalities, which mean the simple representations of design, were evaluated by users and interpreted by the groups to improve the prototype usability. All functionalities were obtained previously from questionnaires, surveys, and observations and resulted in lists of users' needs which the groups consider important to product design. Each group created prototypes containing three or four functionalities for testing their concepts. 
Dividing the concept of the prototypes into functionalities allows the separate visualization of each part of the prototype that meets the needs of users and which part needs improvement. The test of prototype functionalities allowed the groups to study the user's needs and reactions, identify critical situations of the functionalities and establish alternative options or even the feasibility of the prototype concept. This allows coordination and adjustments in the design of each functionality determined, in addition to providing the groups learning and creation of new opportunities from users on each functionality.

The method also helped the engineering students to understand the importance of prototyping for the product development process. Using prototypes in product development supports to create a common reference for the project and clarify communication between developers and users, improving the understanding of the context of use and the product value to be delivered (Neubeck et al., 2016). Groups reports mention those prototype's support through the method:

It was possible to reassess the ideas and concepts and refine to the level considered ideal after the prototyping tests, obtaining the desired result by the group. (Group 2).

After testing with users, it was possible to evaluate our concepts and solutions incorporated in the prototype. Positive and negative points were raised, as well as suggestions on how we could improve our project even further. (Group 3).

It is worth mentioning the relevance of prototyping for the testing phase, which gave us a much broader view of the problems and improvements that should be implemented, bringing opinions and ideas beyond what we, the designers, could have imagined. (Group 4).

The case research also emerged one UCD practice identified by ISO 4291-210 standard: evaluate the design. This fourth activity of UCD practice had been detected in two different manners: before and after users' involvement.

Before user involvement, all groups were required to review their prototype functionalities when performing the pre-test and six of the eight groups studied had made prototype adjustments. Those adjustments took place through group discussions fostered by completing the Concept Test chart. The discussions promoted a review of the prototype functionalities and six groups were able to anticipate and correct possible errors or difficulties that would happen. According to spectators' reports, the changes resulted in project improvements, before the user involvement stage.

We can analyze that by using the method chart the groups passively involved users when the team of developers acts as the users, so they put themselves in the user's shoes, as defined by Zhang \& Dong (2016). This step helps to raise initial clues that will be anticipated and trace the origin of the problems in the initial phase of the project, to avoid future mistakes and confusions.

After user involvement, all groups were able to adjust their prototype functionalities to align users' needs with the design objective. The decisions are taken consist of maintaining, discarding, or changing prototype functionalities. Those project adjustments were interpreted by coding the groups' reports.

As with the importance of prototyping, engineering students recognized in the reports the importance of considering the user to develop good products. The groups' reports reveal that they perceived that UCD projects can result in successful product development processes:

In particular, it was possible to notice how the contact with users is extremely important since the stages of interviews and tests of the prototype with users were essential to identify problems and possible improvements that would hardly have been observed without this contact. From this interaction with users, it was possible to receive feedback and thus think of ideas to improve existing trash cans and from tests, with them, it was possible to notice errors in the project in addition to possible improvements. (Group 7).

The evaluation of the method verifies whether the studied groups reached the objective of the Concept Test: testing prototypes functionalities with users. The evaluation took place by analyzing two elements contained in the research data: the proposed sequence of steps and obtaining the objectives of the method.

\subsection{Concept test steps}

The data in the Concept Test chart were completed satisfactorily by all groups in the first stage of the application of the method. During the analysis of the spectators' audio, there were no difficulties for the groups to follow the steps indicated in the guide. The following reports are from Spectator \#3:

They accompany the description of the method on paper [guide] almost all the time.

They filled in all the functions/ideas and started to discuss what would be the free tests and guided tests. 
For the first function' recycle bin functionality 'they opted for the free trial to see if the user identifies the prototype as a recycle bin and what type of waste [organic or not] the user throws in the recycle bin.

The audios indicate that the group used the guide and correctly followed the steps to complete the chart. The choice of guided or free tests was one of those steps. The free test chosen by Group 3 (to analyze the user's reactions when using the product) was under the description of the objective of this test in the guide. The same fact happened for the other choices of all groups that participated in the research.

There were reports about the possibility of choosing more than one test for the same function and the use of a test for different functions. Although not described in the method guide, this possibility did not affect the choice of groups for the types of tests.

The audios also allowed us to analyze that some groups had doubts about the sequence of filling out the test. Groups 2, 5, 6 (Figure 7a) and 7 had doubts about the use of more than one test (guided and free) by prototype function and how they use the adhesive notes for this. Group 8 (Figure 7b) exceeded the space on the board reserved for a function due to the number of sticky notes in a single line. These groups had to use two lines per function.

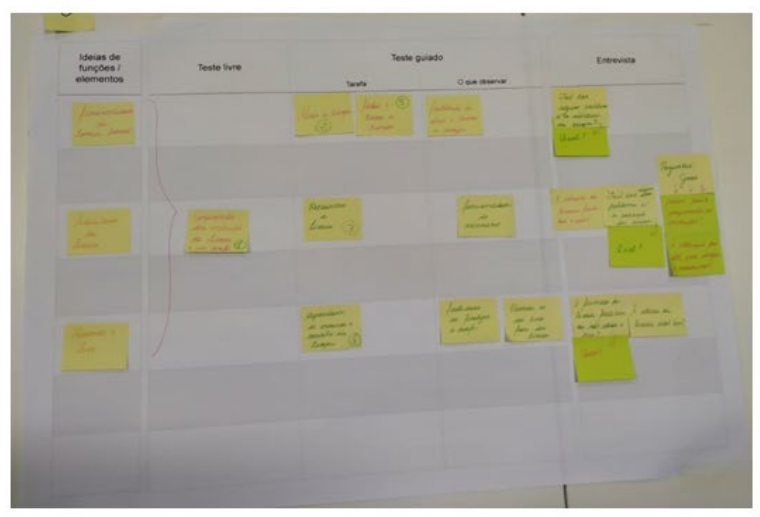

(a)

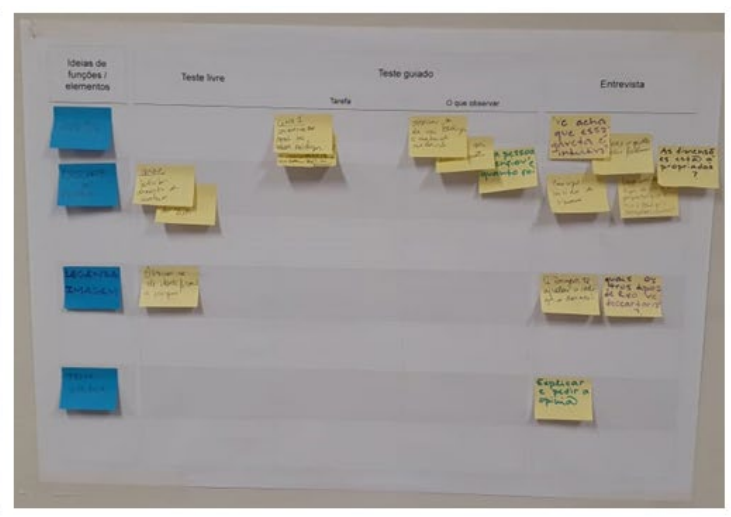

(b)

Figure 7. Method chart of the groups 6 and 8

Concerning filling in the rows (functions) and columns (tests), groups 3 and 6 chose to fill the chart with all the functionalities to be tested and then include which types of tests and information correspond to each functionality. The other groups $(1,2,4,5,7$, and 8$)$ started by defining functionality and inserted the types of tests and information for this functionality, and then inserted the second functionality.

When completing the filling and planning the execution of the method, groups 5, 7, and 8 identified that the order in which the functionality would be tested is important for the user's involvement. All groups, therefore, were instructed to order the function test using sticky notes.

The observers' audios also reported that the majority of the groups $(1,3,4,5,7$, and 8$)$ made modifications to the prototypes during the test planning phase. Groups 1,4 , and 8 realized that a need to decrease the prototype height so users can carry out the cleaning tasks. Group 8 also added symbols to assist the written identification of suitable waste discards. Group 3 noted a need to add written identification to the drawings indicating the appropriate residue for the prototype before user involvement through brainstorming with its members. Group 5 opted for a transparent material in their prototype that facilitates the user's perception. Group 7 verified a need to fix the prototype attached to a wall to help the test of functionality.

\subsection{Concept test objective}

The groups reported that the method used collaborated to obtain comments from users, understand their needs, and improve the prototype. Groups' reports and spectators" audios confirm that the groups used the Test of Concept method satisfactorily. Data related to Group 2 are reported below.

The first user ended the interaction and the group went to the board to check if something was missing. Another user was selected to take the test, and they are always consulting the board to check the activities they had thought about and the questions asked. (Spectator \#5).

You can see that they are really enjoying the test and this is really cool. (Spectator \#5). 
After users interacted with the prototype and answered the questions, it was possible to obtain feedback and understand the changes that were considered good and those that need to be improved. (Groups report).

We can conclude the importance that the tests with users had for obtaining feedback on the prototype [...] and also the importance that the concept test method had with the experts in helping us to make a good preparation for the tests, assisting us in how to interact better with users and what to observe/test more practically. (Group report).

The data allow us to analyze that Group 2 consulted the information to support the involvement during the second stage of the method. Obtaining information to better understand users' needs and the importance of the method to perfect the project was reported. The other groups, as well as Group 2, were able to obtain information about the needs of the users who collaborated with the development of the project.

\section{Conclusions}

The case research of this work demonstrates the effectiveness of the Concept Test method to assist groups of developers. Eight groups of engineering students used the method to engage users in their projects through prototypes. The projects were part of the evaluation of a course in the Materials Engineering course at a Brazilian public university.

Analysis of the collected data demonstrates that thinking about prototype functions when involving users is extremely beneficial for engineering students. The functions collaborated so that the users involved in the research were able to provide concrete data about the product in each prototype functionality. The groups of developers, through the prototype functionalities, were able to explore specific parts of the prototype that impact the success of the project. The use of functionalities, therefore, assists users without any expertise to provide product information.

Groups of engineering students were able to refine the prototype in the planning phase. The use of the method provided the groups with the identification and prevention of errors that would impact the test execution phase. The method, therefore, brought benefits already during the planning and also after the tests with users.

Concept test is believed to be effective for the developer team to involve users in their projects through prototypes, but they should work as a complement to the requirements management methods in the other stages of development. The engineering students who participated in the case research had already used other methods to identify users, their needs, generate solutions, and build their prototypes. The Concept Test alone, therefore, is not able to guarantee the usability of the products to be developed. Methods such as persona, empathy map, card sorting, and storyboarding should be part of the scope of the product design, in addition to the Concept Test.

\section{Acknowledgements}

This research was supported by the Coordination of Improvement of Higher Education Personnel (CAPES).

\section{References}

Abras, C., Maloney-Krichmar, D., \& Preece, J. (2004). User-centered design. In W. Bainbridge (Ed.), Encyclopedia of humancomputer interaction. Thousand Oaks: Sage.

Ahmed, S., Wallace, K. M., \& Blessing, L. T. M. (2003). Understanding the differences between how novice and experienced designers approach design tasks. Research in Engineering Design, 14(1), 1-11. http://dx.doi.org/10.1007/s00163-002-0023-z.

Alcoforado, M. G., Paschoarelli, L. C., \& Silva, J. C. P. D. (2015). Metodologia centrada nos protótipos: um caminho para inclusão de usuários no processo de design. Blucher Design Proceedings, 2(1), 878-893.

Barrington, S. (2007). Usability in the lab: techniques for creating usable products. Journal of Laboratory Automation, 12 (1), 6-11. http://dx.doi.org/10.1016/j.jala.2006.08.004.

Baxter, W. L., Aurisicchio, M., \& Childs, P. R. N. (2015). A psychological ownership approach to designing object attachment. Journal of Engineering Design, 26(4-6), 140-156. http://dx.doi.org/10.1080/09544828.2015.1030371.

Camburn, B., Dunlap, B., Gurjar, T., Hamon, C., Green, M., Jensen, D., Crawford, R., Otto, K., \& Wood, K. (2015). A systematic method for design prototyping. Journal of Mechanical Design, 137(8), 81102-81103. http://dx.doi.org/10.1115/1.4030331.

Campese, C. (2019). Proposta de um framework para aplicação de UCD (User-Centred Design) para pequenas empresas desenvolvedoras de produtos eletromédicos [Doctoral dissertation]. Universidade de São Paulo, São Carlos.

Campese, C., Amaral, D. C., \& Mascarenhas, J. (2020). Restating the meaning of UCD and HCD for a new world ff design theories. Interacting with Computers, 32(1), 33-51. http://dx.doi.org/10.1093/iwc/iwaa003.

Campese, C., Scatolin, J. L., Esposto, R. F. S., \& Costa, J. M. H. (2015). Estudo dos métodos de UCD. In Anais do $10^{\circ}$ Congresso Brasileiro de Gestão da Inovação e Desenvolvimento de Produtos (pp. 1-12). Itajubá: IGDP.

Chrissis, M., Konrad, M., \& Shrum, S. (2013). CMMI: guidelines for process integration and product improvement. Upper Saddle River: Addison-Wesley. 
Cooper, R. G. (2011). Winning at new products: creating value through innovation. New York: Basic Books.

Crawford, M., \& Di Benedetto, A. (2015). Gestão de novos produtos (11. ed.). Porto Alegre: McGraw Hill Brasil. Retrieved in 2021, February 24, from https://books.google.com.br/books?hl=pt-

BR\&1r $=\& i d=J w 7 s C g A A Q B A J \& o i=$ fnd $\&$ pg $=$ PR1\&dq $=$ Crawford + e+Benedetto $+(2015,+$ p.+109$)+$ gestão + de + novos + produtos \&ots $=$ 1bqbP4h6Ve\&sig=yLnlCcCUloXoLPXVOQNywG5PLFE

de la Hidalga, A. N., Hardisty, A., \& Jones, A. (2016). SCRAM-CK: applying a collaborative requirements engineering process for designing a web-based e-science toolkit. Requirements Engineering, 21(1), 107-129. http://dx.doi.org/10.1007/s00766-014-0212-0.

Deininger, M., Daly, S. R., Sienko, K. H., \& Lee, J. C. (2017). Novice designers' use of prototypes in engineering design. Design Studies, 51, 25-65. http://dx.doi.org/10.1016/j.destud.2017.04.002.

Eppinger, S., \& Ulrich, K. (2015). Product design and development (4th ed.). New York: McGraw-Hill Higher Education.

Gladden, G. R. (1982). Stop the life-cycle, I want to get off (ACM SIGSOFT Software Engineering Notes, Vol. 7, No. 2). Retrieved in 2021, February 24, from http://www-public.imtbs-tsp.eu/ gibson/Teaching/Teaching-ReadingMaterial/Gladden82.pdf

Göransson, B. (2001). Usability design: a framework for designing usable interactive systems in practice. Uppsala: Uppsala Universitet.

Gulliksen, J., Göransson, B., Boivie, I., Blomkvist, S., Persson, J., \& Cajander, Å. (2003). Key principles for user-centred systems design. Behaviour \& Information Technology, 22(6), 397-409. http://dx.doi.org/10.1080/01449290310001624329.

International Organization for Standardization - ISO. (2010). ISO 9241-210: ergonomics requirements for office work with terminals (VDT). Part 11: guidance on usability. Geneva: ISO.

Karlsson, C. (2016). Research methods for operations management. London: Routledge.

Kelley, T. (2005). The ten faces of innovation. London: Profile Books.

Mao, J.-Y., Vredenburg, K., Smith, P. W., \& Carey, T. (2005). User-centered design practice. Communications of the ACM, 48(3), 105-109. http://dx.doi.org/10.1145/1047671.1047677.

Miles, M. B., Huberman, M. A., \& Saldaña, J. (2014). Qualitative data analysis: a methods sourcebook. Zeitschrift Fur Personalforschung, 28(4), 485-487. http://dx.doi.org/10.1177/239700221402800402.

Miller, W. S., \& Summers, J. D. (2013). Investigating the use of design methods by capstone design students at Clemson University. International Journal of Technology and Design Education, 23(4), 1079-1091. http://dx.doi.org/10.1007/s10798-012-9227-3.

Neubeck, L., Coorey, G., Peiris, D., Mulley, J., Heeley, E., Hersch, F., \& Redfern, J. (2016). Development of an integrated e-health tool for people with, or at high risk of, cardiovascular disease: the Consumer Navigation of Electronic Cardiovascular Tools (CONNECT) web application. International Journal of Medical Informatics, 96, 24-37. http://dx.doi.org/10.1016/j.ijmedinf.2016.01.009.

Nguyen-Duc, A., Wang, X., \& Abrahamsson, P. (2017). What influences the speed of prototyping? An empirical investigation of Twenty Software Startups. Lecture Notes in Business Information Processing, 283, 20-36. http://dx.doi.org/10.1007/978-3-31957633-6_2.

Norman, D. A. (1988). The psychology of everyday things. New York: Basic Books.

Preece, J., Rogers, Y., Rogers, H. S.-Y., \& Phoenix, H. S. (2002). Beyond human-computer interaction. Chichester : John Wiley \& Sons.

Rippon, S. (2006). Usability, user-centered design (UCD), and FOSS OSDC conference 2006. Scott Rippon Consulting. Retrieved September 24, 2020, from http://www.monash.edu/

Rozenfeld, H., Forcellini, F., Amaral, D. C., de Toledo, J. C., Silva, S. L., Alliprandini, D. H., \& Scalice, R. K. (2006). Gestão de projetos em desenvolvimento de produtos. São Paulo: Saraiva.

Rudd, J., Stern, K., \& Isensee, S. (1996). Low vs. high-fidelity prototyping debate. Interaction, 3(1), 76-85.

http://dx.doi.org/10.1145/223500.223514.

Schrage, M. (2014). The innovator's hypothesis: how cheap experiments are worth more than good ideas. Cambridge: MIT Press.

Siebenhandl, K., Schreder, G., Smuc, M., Mayr, E., \& Nagl, M. (2013). A user-centered design approach to self-service ticket vending machines. IEEE Transactions on Professional Communication, 56(2), 138-159. http://dx.doi.org/10.1109/TPC.2013.2257213.

Viitaniemi, J., Aromaa, S., Leino, S.-P., Kiviranta, S., \& Helin, K. (2010). Integration of user-centred design and product development process within a virtual environment (VTT Working Papers, No. 147). Finland: VTT.

Wilkie, A. (2014). Prototyping as event: designing the future of obesity. Journal of Cultural Economics, 7(4), 476-492. http://dx.doi.org/10.1080/17530350.2013.859631.

Zhang, B., \& Dong, H. (2016). User involvement in design: the four models. Lecture Notes in Computer Science, $9754,141-152$. http://dx.doi.org/10.1007/978-3-319-39943-0_14. 
Appendix 1. Spectors protocol.

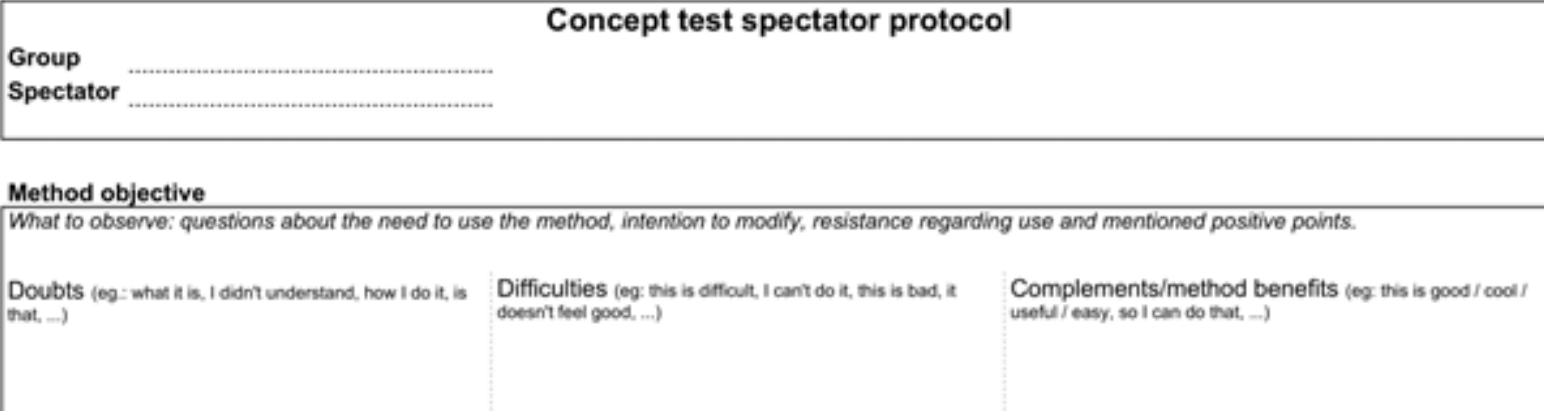

Method results

What fo obsorve; identified results that will halp with prototype festing with users

$\begin{array}{lll}\text { Doubts } & \text { Difficulties } & \text { Complements/method benefits }\end{array}$

Instructions comprehension

1) Understanding steps 1 and $2(2,1,2.2$ and 2.3) What to observe: the steps wow followed and were clear

Doubts Difficulties

Complements/method benefits

2) Filling out the chart. What to observe: amount of information entered, filing in the post ie, insertion in the correct place, ofc.

Doubts Difficulties Complements/method benefits

1) Identifing function / element ideas (Corresponds to step 1)

2) Choice of test to use: free or guided (Corresponds to step 2)

3) Fill out the free test and its information / activities to insert on the chart (Corresponds to step 2.1)

4) Fill out the guided test and its information / activities and what to observe on the chart (Corresponds to step 2.2)

5) Fill out the interviews column and relate the it to the concept function to be tested (Corresponds to step 2.3)

Doubts

Difficulties

Complements/method benefits 